\title{
Correction to: Relationship between the seasonal changes in plasma testosterone and thyroxine concentrations with sperm cryoresistance in Gabon bucks
}

\author{
María Noel Viera $^{1}\left[\right.$ - Rodolfo Ungerfeld ${ }^{1} \cdot$ Rosario Velázquez $^{2} \cdot$ Julián Santiago-Moreno $^{2}$
}

Published online: 29 July 2021

(c) Springer Nature B.V. 2021

Correction to: Tropical Animal Health and Production (2021) 53:370

https://doi.org/10.1007/s11250-021-02830-z

In the original version of this article, the given and family names of all authors were incorrectly structured. The names Viera María Noel, Ungerfeld Rodolfo, Velázquez Rosario, and Santiago-Moreno Julián should be presented as María Noel Viera, Rodolfo Ungerfeld, Rosario Velázquez, Julián Santiago-Moreno. These are now correctly presented above.

The original article has been corrected.

Publisher's note Springer Nature remains neutral with regard to jurisdictional claims in published maps and institutional affiliations.

The original article can be found online at https://doi.org/10.1007/ s11250-021-02830-z.

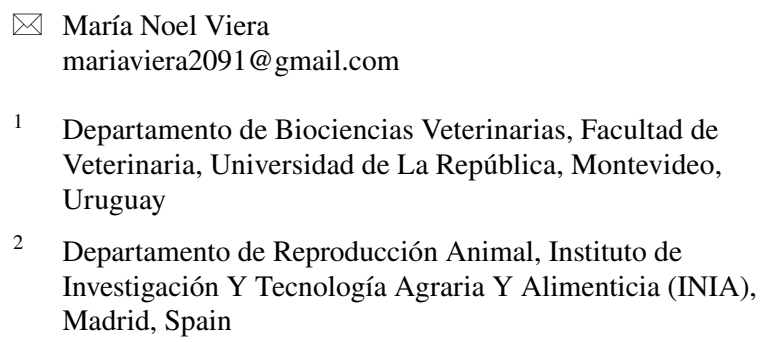

1 Departamento de Biociencias Veterinarias, Facultad de Veterinaria, Universidad de La República, Montevideo, Uruguay

2 Departamento de Reproducción Animal, Instituto de Investigación Y Tecnología Agraria Y Alimenticia (INIA), Madrid, Spain 